\title{
Right ventricular function parameters in pulmonary hypertension: echocardiography vs. cardiac magnetic resonance
}

\author{
Anna Werther Evaldsson ${ }^{1 *}$ (D), Anthony Lindholm², Raluca Jumatate', Annika Ingvarsson ${ }^{1}$, Gustav Jan Smith ${ }^{1}$, \\ Johan Waktare ${ }^{3}$, Göran Rådegran', Anders Roijerr', Carl Meurling ${ }^{1}$ and Ellen Ostenfeld ${ }^{2}$
}

\begin{abstract}
Background: Right ventricular (RV) function is a major determinant of outcome in patients with pulmonary hypertension. Cardiac magnetic resonance (CMR) is gold standard to assess RV ejection fraction (RVEF $F_{C M R}$ ), however this is a crude measure. New CMR measures of RV function beyond RVEF ${ }_{C M R}$ have emerged, such as RV lateral atrioventricular plane displacement $\left(\mathrm{AVPD}_{\text {lat }}\right)$, maximum emptying velocity $\left(\mathrm{S}_{\mathrm{CMR}}\right)$, RV fractional area change $\left(\mathrm{FAC}_{\mathrm{CMR}}\right)$ and feature tracking of the RV free wall (FWS ${ }_{C M R}$ ). However, it is not fully elucidated if these CMR measures are in parity with the equivalent echocardiography-derived measurements: tricuspid annular plane systolic excursion

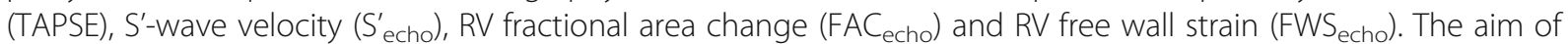
this study was to compare regional RV function parameters derived from CMR to their echocardiographic equivalents in patients with pulmonary hypertension and to RVEF $C M R$.
\end{abstract}

Methods: Fifty-five patients (37 women, $62 \pm 15$ years) evaluated for pulmonary hypertension underwent CMR and echocardiography. $\mathrm{AVPD}_{\text {lat, }} \mathrm{S}_{\mathrm{CMR}}{ }_{\mathrm{C}}, \mathrm{FAC}_{\mathrm{CMR}}$ and $\mathrm{FWS} \mathrm{C}_{\mathrm{CMR}}$ from cine 4-chamber views were compared to corresponding echocardiographic measures and to RVEF $\mathrm{FMR}_{\mathrm{R}}$ delineated in cine short-axis stack.

Results: A strong correlation was demonstrated for FAC whereas the remaining measurements showed moderate correlation. The absolute bias for $\mathrm{S}^{\prime}$ was $2.4 \pm 3.0 \mathrm{~cm} / \mathrm{s}$ (relative bias $24.1 \pm 28.3 \%$ ), TAPSE/AVPD lat $5.5 \pm 4.6 \mathrm{~mm}$ $(33.2 \pm 25.2 \%)$, FWS $4.4 \pm 5.8 \%(20.2 \pm 37.5 \%)$ and for FAC $5.1 \pm 8.4 \%(18.5 \pm 32.5 \%)$. In correlation to RVEF $F_{C M R}$, FAC CMR $_{\text {CM }}$

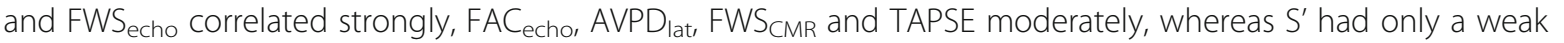
correlation.

\footnotetext{
* Correspondence: anna.werther_evaldsson@med.lu.se

'Lund University, Department of Clinical Sciences Lund, Cardiology, Section

for Heart Failure and Valvular Disease, Skane University Hospital, Lund,

Sweden

Full list of author information is available at the end of the article
}

(c) The Author(s). 2020 Open Access This article is licensed under a Creative Commons Attribution 4.0 International License, which permits use, sharing, adaptation, distribution and reproduction in any medium or format, as long as you give appropriate credit to the original author(s) and the source, provide a link to the Creative Commons licence, and indicate if changes were made. The images or other third party material in this article are included in the article's Creative Commons licence, unless indicated otherwise in a credit line to the material. If material is not included in the article's Creative Commons licence and your intended use is not permitted by statutory regulation or exceeds the permitted use, you will need to obtain permission directly from the copyright holder. To view a copy of this licence, visit http://creativecommons.org/licenses/by/4.0/. The Creative Commons Public Domain Dedication waiver (http://creativecommons.org/publicdomain/zero/1.0/) applies to the data made available in this article, unless otherwise stated in a credit line to the data. 


\begin{abstract}
(Continued from previous page)
Conclusion: This study has demonstrated a moderate to strong correlation of regional CMR measurements to corresponding echocardiographic measures. However, biases and to some extent wide limits of agreement, exist between the modalities. Consequently, the equivalent measures are not interchangeable at least in patients with pulmonary hypertension. The echocardiographic parameter that showed best correlation with RVEF CMR was

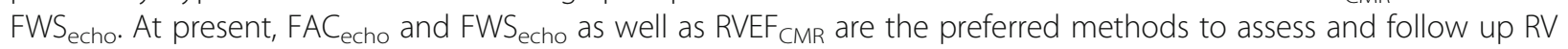
function in patients with pulmonary hypertension. Future investigations of the CMR right ventricular measures, beyond RVEF, are warranted.
\end{abstract}

Keywords: Echocardiography, Cardiac magnetic resonance, Right ventricular function, Validation study

\section{Background}

Right ventricular (RV) function is a major determinant of outcome in patients with pulmonary hypertension $[1$, 2]. Comprehensive assessment of RV function is challenging and measurements beyond volumetric changes, such as RV ejection fraction (EF), are eligible [1, 3, 4]. However, RVEF is a crude measure and more subtle methods are warranted for assessing patients with pulmonary hypertension.

First-line modality for evaluation of cardiac morphology and function in clinical practice is echocardiography. Nevertheless, RV assessment by echocardiography is vulnerable to the complex geometry of the $\operatorname{RV}[5,6]$. The drawback of most of the echocardiographic measurements is that they are estimates of longitudinal function. Since approximately $80 \%$ of the RV stroke volume is generated from longitudinal contribution [4], in clinical use they are considered to reflect global RV function. However, in patients with a pressure overloaded $\mathrm{RV}$, the contraction pattern changes significantly from primarily longitudinal to circumferential contraction [7]. Conventionally, RV function by echocardiography is estimated by tricuspid annular plane systolic excursion (TAPSE), $\mathrm{S}^{\prime}$-wave velocity $\left(\mathrm{S}_{\text {echo }}\right), \mathrm{RV}$ fractional area change $\left(\mathrm{FAC}_{\text {echo }}\right)$ and myocardial strain derived from the RV lateral free wall $\left(\mathrm{FWS}_{\text {echo }}\right)$ [3]. $\mathrm{FWS}_{\text {echo }}$ has shown promising results in assessment of RV longitudinal systolic function [8-11] and has consequently been included in guidelines [3]. In clinical practice, $\mathrm{FAC}_{\text {echo }}$ is more commonly used as a surrogate to RVEF [3].

Cardiac magnetic resonance imaging (CMR) is considered "gold standard" for assessing RV volumes as well as ejection fraction $\left(\operatorname{RVEF}_{\mathrm{CMR}}\right)[12,13]$ and is advantageous as it overcomes the echocardiographic limitations [5, 14]. New CMR measures of RV function equivalent to echocardiography-derived measurements have emerged beyond $\mathrm{RVEF}_{\mathrm{CMR}}$ such as; RV atrio-ventricular plane displacement in the lateral wall $\left(\mathrm{AVPD}_{\text {lat }}\right)[4,15]$, maximum emptying velocity derived from the AVPD curve $\left(\mathrm{S}_{\mathrm{CMR}}\right)$ [16], $\mathrm{RV}$ fractional area change $\left(\mathrm{FAC}_{\mathrm{CMR}}\right)$ [17] and RV free wall strain $\left(\mathrm{FWS}_{\mathrm{CMR}}\right)$ [18]. $\mathrm{FWS}_{\mathrm{CMR}}$ has been shown to have an added value to $R V E F_{C M R}$ in patients with pulmonary hypertension [19]. However, it is not fully explored how these measures are in parity with the echocardiographic equivalents and to what extend they relate to $R V E F_{C M R}$. The aim of this study was to compare conventional and new RV function parameters derived from CMR to their echocardiographic equivalents in patients with pulmonary hypertension. Secondly, we aimed to investigate how these measures are associated with $\mathrm{RVEF}_{\mathrm{CMR}}$.

\section{Methods \\ Patient population}

Between January 2012 and July 2017 at Skåne University Hospital, Lund, 90 consecutive patients with pulmonary hypertension were evaluated prospectively with echocardiography and CMR [11]. Diagnosis of pulmonary hypertension were set by right heart catheterization and was defined as mean pulmonary arterial pressure $\geq 25$ $\mathrm{mmHg}$ and was characterized as precapillary when pulmonary artery wedge pressure $<15 \mathrm{mmHg}$ according to current guidelines [20]. Medical records were used for retrieving patient characteristics. Patients were included if $\leq 14$ days between $C M R$ and echocardiography given no change in medical treatment or clinical status during this time. Patients were excluded if atrial fibrillation was present $(n=15)$ or if echocardiographic image quality were inadequate $(n=20)$ owing to full visualization of the RV was not possible despite meticulous attempts $(n=8)$ or when the endocardial borders were not traceable for $\mathrm{FAC}_{\text {echo }}$ and $\mathrm{FWS}_{\text {echo }}$ measurements $(n=12)$.

\section{Echocardiography}

Echocardiographic images were obtained by an S5-1 transducer using an iE33 platform (Philips Healthcare, Eindhoven, NL). Acquisition and assessment were performed according to guidelines [3], by senior sonographers. RV function was assessed by the conventional parameters TAPSE, $\mathrm{S}_{\text {echo, }} \mathrm{FAC}_{\text {echo }}$ and $\mathrm{FWS}_{\text {echo }}$ according to current guidelines from an apical RV focused 4-chamber view using Xcelera (Philips Healthcare, Eindhoven, NL) (Fig. 1) [3]. Framerate for 2-D images was $50-80 \mathrm{~Hz}$. A dedicated software for strain analysis 

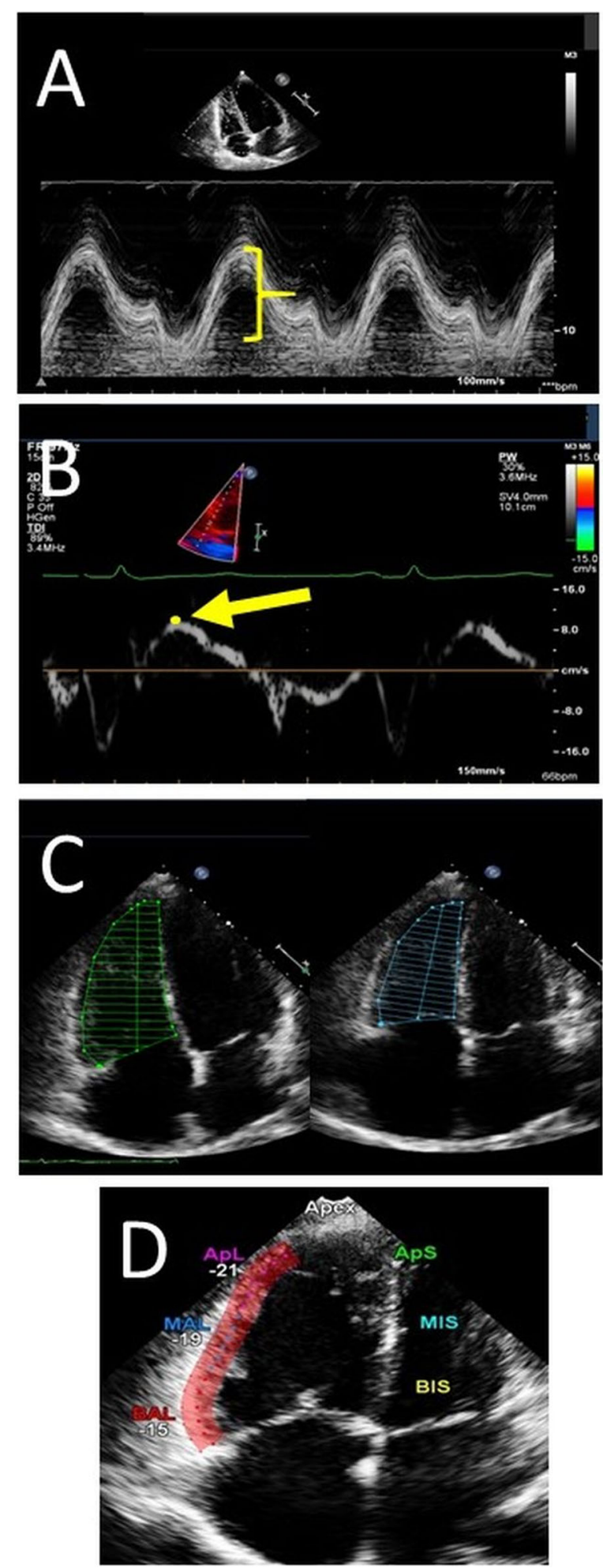

Fig. 1 Illustration of echocardiographic measures for assessing right ventricular function. a: TAPSE (tricuspid annular plane systolic excursion), b: $S_{\text {echo }}$ (S'-wave velocity), c: FAC echo (fractional area change), d: FWS echo (free wall strain) was used for offline analysis (CMQ, Q-lab 10.3, Philips Healthcare). At end-diastole the region of interest was traced along the RV endocardium and a propagated tracking was performed. Manual correction was performed if there was inappropriate tracking. Calculation of $\mathrm{FWS}_{\text {echo }}$ was made as an average of the three peak systolic strains values along the RV free wall. Low intraand inter-observer variability within our research group has previously been validated and published [10].

\section{Cardiac magnetic resonance imaging}

CMR was obtained as described previously by our research group [11]. CMR images were assessed using Segment version 2.2 software (http://segment.heiberg.se) [21]. The volumes of the right ventricle and RVEF were derived from manual delineations of end-diastolic and end-systolic endocardial borders in the short-axis stack. RV measurements were traced based on endocardial delineations. Trabeculation and papillary muscles were included in the RV-volumes according to standardized interpretation [22]. The difference between the enddiastolic and end-systolic volumes divided by the enddiastolic volume were used for $\mathrm{RVEF}_{\mathrm{CMR}}$ calculation. $\mathrm{AVPD}_{\text {lat }}, \mathrm{S}_{\mathrm{CMR}}, \mathrm{FAC}_{\mathrm{CMR}}$, and $\mathrm{FWS}_{\mathrm{CMR}}$, were analyzed in the 4-chamber view. $A V P D_{\text {lat }}$ was quantified from a manual input point at the base of the RV free wall in end-diastole with time-resolved automated tracking through the cardiac cycle (Fig. 2a), and $\mathrm{S}_{\text {CMR }}$ was computed as the maximum emptying velocity derived from the time-resolved AVPD curve [16, 23] (Fig. 2b). $\mathrm{FAC}_{\mathrm{CMR}}$ (Fig. 2c) and $\mathrm{FWS}_{\mathrm{CMR}}$ was assessed by tracing the RV endocardium at end-diastole. $\mathrm{FWS}_{\mathrm{CMR}}$ was computed from automated propagated tracking from end-diastole throughout the heart cycle, averaging three regional segmental peak systolic strain values along the RV free wall with manual correction if necessary (Fig. $2 \mathrm{~d})$. Low intra- and inter-observer variability within our research group has previously been validated and published [13, 16, 23].

\section{Statistical analysis}

Continuous data was expressed as mean \pm standard deviation (SD) or median with inter-quartile range [IQR], as appropriate according to normal distribution. Normality was assessed visually from histograms. Categorical data was expressed in absolute numbers and proportion (percentage). Pearson's correlation coefficient ( $r$-values) was used for association between echocardiography and CMR. Degree of correlation between tests was classified as either weak $(\mathrm{r}=0.3-0.5)$, moderate $(0.5-0.7)$, strong (0.7-0.9) or very strong (0.9-1.0) [24]. Bias according to Bland-Altman was computed between modalities [25]. A univariate $\mathrm{T}$-test analysis was performed to detect differences between sexes and between patients with and 


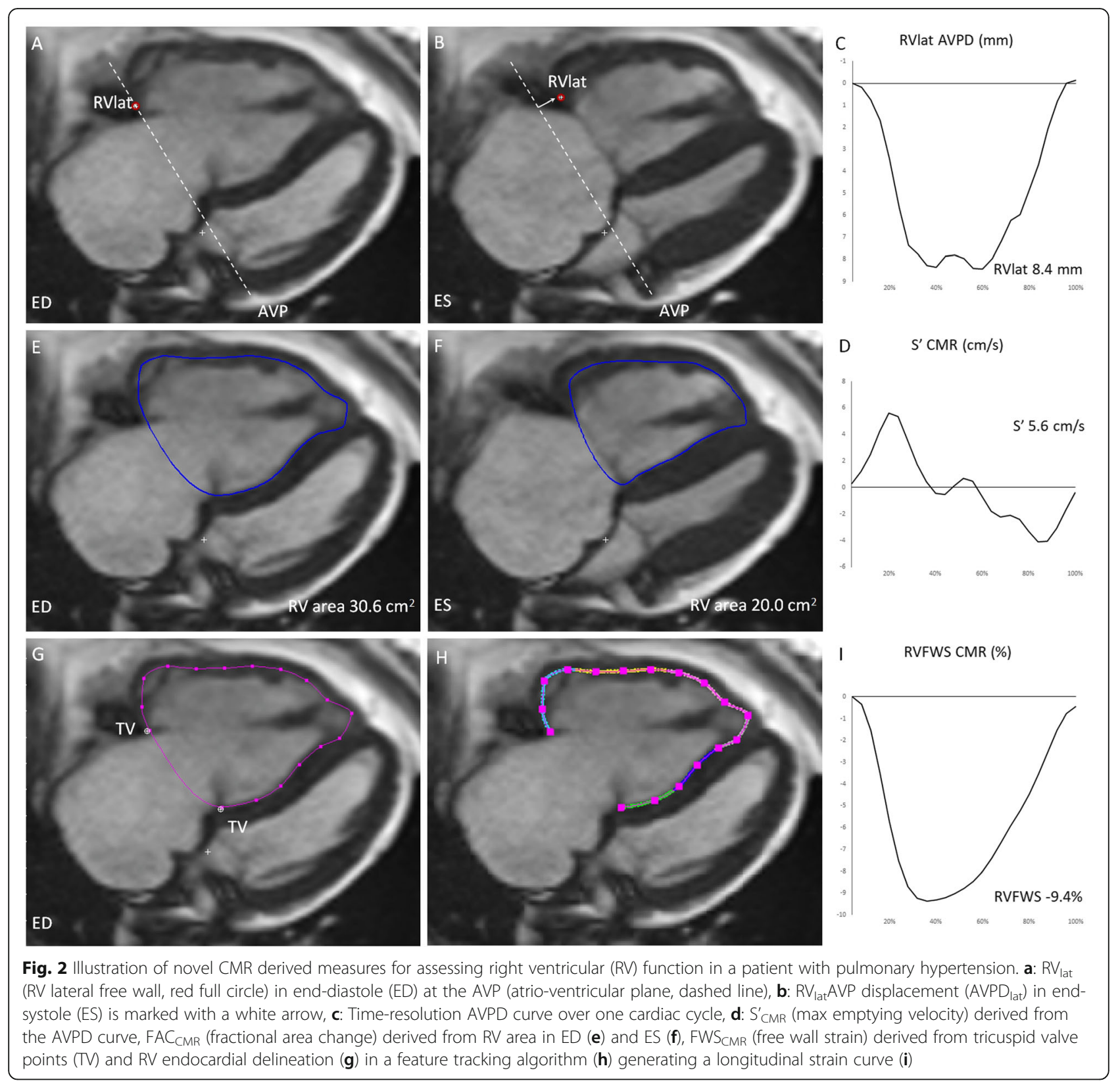

without comorbidities, and a multivariate regression analysis weas performed adjusting of age, sex and comorbidities. T-test and Fischer's exact test were used for sensitivity analysis between the patients with $\mathrm{PAH}$ and the patients without PAH. Values of two-tailed $P<0.05$ were considered statistically significant. Analyses were performed using a commercially available software (IBM, SPSS Statistics, version 25, Chicago, IL, USA).

\section{Results}

\section{Clinical characteristics}

Baseline characteristics of the included 55 patients (37 women, $62 \pm 15$ years) are shown in Table 1 . The median time between echocardiography and CMR was 1 day [1-2 days].

Of the five etiological subclasses of pulmonary hypertension [20], the most common etiologies were pulmonary arterial hypertension $(n=40)$ and chronic thromboembolic pulmonary hypertension $(n=9)$. Median NT-proBNP was $979 \mathrm{ng} / \mathrm{L}$ [329-2286 ng/L]. 18\% of the patients were treated with pulmonary arterial vasodilators (60\% of these with double or triple medication). $87 \%$ of the patients were in WHO-functional class II or III and the median 6-min walk test was $325 \mathrm{~m}$ [200412]. Comorbidities were present in 28 patients (Table 1). Echocardiographic characteristics are shown in 
Table 1 Baseline characteristics for demographic, clinical and laboratory parameters

\begin{tabular}{|c|c|}
\hline Number of patients & 55 \\
\hline Sex (women/men) & $37 / 18(67 / 33)$ \\
\hline Age (years) & $62 \pm 15$ \\
\hline $\operatorname{BSA}\left(m^{2}\right)$ & $1.9 \pm 0.2$ \\
\hline \multicolumn{2}{|l|}{ Etiology of pulmonary hypertension } \\
\hline Group I (pulmonary arterial hypertension, PAH) & $40(73)$ \\
\hline Group II (due to left heart disease) & $5(9)$ \\
\hline Group III (due to lung diseases and/or hypoxia) & $1(2)$ \\
\hline Group IV (due to chronic thromboembolism) & $9(16)$ \\
\hline Group V (unclear and/or multifactorial mechanisms) & $0(0)$ \\
\hline \multicolumn{2}{|l|}{ Laboratory parameters } \\
\hline NT-proBNP (ng/L) & 979 [329-2286] \\
\hline Saturation peripheral (\%) & $93 \pm 4$ \\
\hline \multicolumn{2}{|l|}{ Comorbidites } \\
\hline Diabetes & $14(26)$ \\
\hline Hypertension & $13(24)$ \\
\hline Coronary artery disease & $7(13)$ \\
\hline Chronic obstructive pulmonary diseases & $7(13)$ \\
\hline Obstructive sleep apnea syndrome & $1(3)$ \\
\hline 6-min walking test $(\mathrm{m})$ & $325[200-412]$ \\
\hline \multicolumn{2}{|l|}{ Functional class, NYHA } \\
\hline । & $3(6)$ \\
\hline$\|$ & $29(53)$ \\
\hline III & $19(35)$ \\
\hline IV & $4(7)$ \\
\hline \multicolumn{2}{|l|}{ Medication } \\
\hline $\mathrm{O}_{2}$ & $14(26)$ \\
\hline Diuretics & $26(47)$ \\
\hline Calcium antagonists & $10(18)$ \\
\hline ACE/ARB blockers & $13(24)$ \\
\hline Beta blockers & $14(26)$ \\
\hline Nitrates & $3(6)$ \\
\hline ERA & $8(15)$ \\
\hline PDE5I & $8(15)$ \\
\hline Prostanoids & $1(2)$ \\
\hline sGCS & $1(2)$ \\
\hline
\end{tabular}

Data are expressed as mean $\pm S D$, median [inter-quartile range] or as number (percentage). BSA Body surface area, NT-proBNP brain natriuretic peptide, ACE Angiotensin-Converting Enzyme, ARB Angiotensin Receptor Blockers, ERA Endothelin Receptor Antagonist, PDE5/ Phosphodiesterase type 5 inhibitors, sGCS Guanylate Cyclase Stimulators

Table 2. Echocardiographic parameters were normal concerning TAPSE and $S_{\text {echo }}$ but reduced for $\mathrm{FAC}_{\text {echo }}$ and $\mathrm{FWS}_{\text {echo }}$. Regarding CMR parameters, $\mathrm{RVEF}_{\mathrm{CMR}}$ was reduced compared to reference values, whilst AVP$D_{\text {lat }}$ was normal $[26,27]$. Echocardiographic and CMR
Table 2 Echocardiographic characteristics

\begin{tabular}{ll}
\hline Left heart & \\
IVSd (mm) & $9.8 \pm 2.4$ \\
LVIDd (mm) & $42 \pm 10$ \\
LVPWd (mm) & $8.7 \pm 2.0$ \\
LVEDV (mL) & $77 \pm 36$ \\
LVESV (ml) & $32 \pm 21$ \\
LVEF (\%) & $60 \pm 13$ \\
LA Volume/BSA (mL/m²) & $28 \pm 14$ \\
Right heart & \\
RA volume/BSA (mL/m²) & $39 \pm 23$ \\
RA area (cm $\left.{ }^{2}\right)$ & $22 \pm 7$ \\
RVDd & $37 \pm 6$ \\
RV size inflow (mm) & $48 \pm 9$ \\
RV size mid cavity (mm) & $38 \pm 10$ \\
TR (0-3) & $1.0[0.5-1.5]$ \\
TR gradient (mmHg) & $56 \pm 21$ \\
IVCd (mm) & $19 \pm 6$ \\
\hline Da are exprssed as mean &
\end{tabular}

Data are expressed as mean \pm SD or median [inter-quartile range]. IVSd Intra ventricular septum diameter, LVIDd Left ventricular inner diastolic diameter, LVPWd Left ventricular posterior wall diameter, LVEDV Left ventricular enddiastolic volume, LVEF Left ventricular ejection fraction, LVESV Left ventricular end-systolic volume, LA Left atrium, RA Right atrium, RVDd Right ventricular diastolic diameter, RVEDA Right ventricular end diastolic area, RVESA Right ventricular end systolic area, $R V$ Right ventricle, $T R$ Tricuspid valve regurgitation, TR gradient Trans-tricuspid gradient, IVCd Inferior vena cava diameter

parameters measuring RV systolic function are shown in Table 3. Regarding factors such as sex and comorbidities a slightly lower LVEDV and LVESV were present in women compared to men, and a lower FWS $\mathrm{CMR}_{\mathrm{C}}$ could be shown in patients with compared with those without comorbidities. When adjusting for age, sex and comorbidities using a multilinear regression analysis, $\mathrm{FWS}_{\mathrm{CMR}}$ was the only parameter that was affected $(p=0.019)$. No differences were seen between the patients with PAH $(n=40)$ and those without PAH $(n=15)$ (Supplemental table 1).

\section{Correlation between CMR and echocardiographic measures}

$\mathrm{R}$-values were 0.808 for $\mathrm{FAC}_{\mathrm{CMR}}$ vs. $\mathrm{FAC}_{\mathrm{echo}}, 0.656$ for $\mathrm{FWS}_{\mathrm{CMR}}$ vs. FWS $\mathrm{Fcho}, 0.644$ for $\mathrm{AVPD}_{\text {lat }}$ vs. TAPSE, and 0.599 for $S^{\prime}{ }_{C M R}$ vs. $S_{\text {echor }}$, $(p<0.0001$ for all) (Table 2, Fig. 3). In comparison with $\operatorname{RVEF}_{\mathrm{CMR}}$, the parameters $\mathrm{FAC}_{\mathrm{CMR}}$ and $\mathrm{FWS}_{\text {echo }}$ demonstrated a strong correlation, whilst a moderate correlation was demonstrated with $\mathrm{FAC}_{\text {echo, }} \mathrm{AVPD}_{\text {lat }}$, FWS $\mathrm{CMR}_{\mathrm{C}}$ and TAPSE. A weak correlation with $\mathrm{RVEF}_{\mathrm{CMR}}$ was demonstrated for $\mathrm{S}^{\prime}$ measured by both modalities (Table 2, Fig. 4).

CMR measurements differed significantly in absolute values compared to echocardiographic measures, with 
Table 3 Correlation of echocardiographic and cardiac magnetic resonance imaging measures of right ventricular function

\begin{tabular}{|c|c|c|c|}
\hline & Mean \pm SD (n) & $\begin{array}{l}\text { Correlation with } \\
\text { corresponding CMR parameter, } \\
\text { r-value }\end{array}$ & $\begin{array}{l}\text { Correlation with } \\
\text { RVEF } F_{C M R} \text {, } \\
\text { r-value }\end{array}$ \\
\hline \multicolumn{4}{|l|}{ CMR } \\
\hline RVEF (\%) & $42 \pm 14(55)$ & & \\
\hline $\mathrm{AVPD}_{\text {lat }}(\mathrm{mm})$ & $14 \pm 4(54)$ & & $0.736^{* * *}$ \\
\hline $\mathrm{S}_{\mathrm{CMR}}^{\prime}(\mathrm{cm} / \mathrm{s})$ & $8.8 \pm 3.0(55)$ & & $0.472^{* * *}$ \\
\hline $\mathrm{FAC}_{\mathrm{CMR}}(\%)$ & $35 \pm 13(55)$ & & $0.819^{* * *}$ \\
\hline $\mathrm{FWS}_{\mathrm{CMR}}(\%)$ & $-20.1 \pm 7.7(55)$ & & $0.726^{* * *}$ \\
\hline \multicolumn{4}{|l|}{ Echocardiography } \\
\hline TAPSE (mm) & $19 \pm 6(53)$ & $0.644^{* * *}$ & $0.592^{* * *}$ \\
\hline $\mathrm{S}_{\text {echo }}^{\prime}(\mathrm{cm} / \mathrm{s})$ & $11.3 \pm 3.5(53)$ & $0.599^{* * *}$ & $0.385^{* *}$ \\
\hline $\mathrm{FAC}_{\text {echo }}(\%)$ & $30 \pm 14(55)$ & $0.808^{* * *}$ & $0.681^{* * *}$ \\
\hline FWS $_{\text {echo }}(\%)$ & $-15.7 \pm 4.8(55)$ & $0.656^{* * *}$ & $0.778^{* * *}$ \\
\hline
\end{tabular}

$S^{\prime}{ }_{C M R}$ and $A_{V P D}$ lat being lower and $F W_{C M R}$ and FAC $_{\text {CMR }}$ higher (Table 2, Fig. 3). The absolute bias for S' was $2.4 \pm 3.0 \mathrm{~cm} / \mathrm{s}$ (relative bias $24.1 \pm 28.3 \%$ ), TAPSE/ $\mathrm{AVPD}_{\text {lat }} 5.5 \pm 4.6 \mathrm{~mm} \quad(33.2 \pm 25.2 \%)$, FWS $4.4 \pm 5.8 \%$ $(20.2 \pm 37.5 \%)$ and for FAC $5.1 \pm 8.4 \%(18.5 \pm 32.5 \%)$.

\section{Discussion}

To our knowledge, this is the first comprehensive study comparing conventional and new RV function parameters derived from CMR to their echocardiographic equivalents in patients with pulmonary hypertension. Our results indicate strong to moderate correlation of CMR measures of RV function to corresponding echocardiographic parities. However, there are biases that needs to be addressed. As such, lowest relative bias was shown for FAC, then FWS, $S$ ' and highest was for TAPSE/AVPD lat. In comparison with $\mathrm{RVEF}_{\mathrm{CMR}}$, a strong correlation was demonstrated for $\mathrm{FAC}_{\mathrm{CMR}}$ and $\mathrm{FWS}_{\text {echo, }}$, whilst a moderate correlation was demonstrated for $\mathrm{FAC}_{\text {echo, }} \mathrm{AVPD}_{\text {lat }}, \mathrm{FWS}_{\mathrm{CMR}}$ and TAPSE, respectively. Only a weak correlation was demonstrated for S' measured by both modalities.

\section{Comparison between corresponding echocardiographic and CMR measurements}

Our results demonstrated a moderate correlation for $\mathrm{AVPD}_{\text {lat }} / \mathrm{TAPSE}$. These are measures of longitudinal contraction, and the longitudinal contribution accounts for approximately $80 \%$ of the RV stroke volume in normal hearts [4]. TAPSE is widely used for echocardiographic assessment of RV function [3], however the value as a prognostic marker in pulmonary hypertension has been debated and has been withdrawn as a risk marker [28]. As the amplitude of TAPSE can be caused by a passive translation movement (i.e. pseudonormalisation), it can be questioned as a marker of true RV systolic function in pulmonary hypertension [29]. Other reasons to defer using TAPSE as a risk marker in the guidelines is the angle dependency. $A V P D_{\text {lat }}$ is a relatively new and sparsely evaluated method, and not referenced in consensus documents for CMR [22]. We found $A V P D_{\text {lat }}$ to be decreased in patients with pulmonary hypertension in alignment with a prior study [15, 17], however, the prognostic value of altered $A V P D_{\text {lat }}$ in pulmonary hypertension remains to be investigated.

In our study, the highest bias was demonstrated for

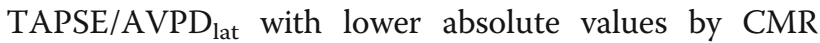
compared to echocardiography. This is an unexpected finding since $\mathrm{AVPD}_{\text {lat }}$ is considered to be less angle dependent than the measurements of TAPSE. Consequently, the bias is probably methodological since they are measured from differently obtained 4-chamber views. In CMR, acquisition of the 4-chamber view is planned from the short-axis view to perfectly rotated into the RV focused view [3]. These adjustments are not possible with echocardiography. Furthermore, the differences in temporal resolution (i.e. framerate is higher using echocardiography) could explain some of the bias between modalities.

S' showed a moderate correlation between echocardiography and CMR. $S_{\text {CMR }}$ has only been described twice previously $[16,23]$ and this is the first study to compare $S^{\prime}{ }_{C M R}$ to the echocardiographic equivalent. The disadvantage of $S_{\text {echo }}^{\prime}$ not being representative for RV global function is substantial since it only measures the velocity in one specific point in the basal segment of the RV lateral wall [3]. Both $S_{\text {echo }}$ and TAPSE have in previous studies been presented within normality in pulmonary 


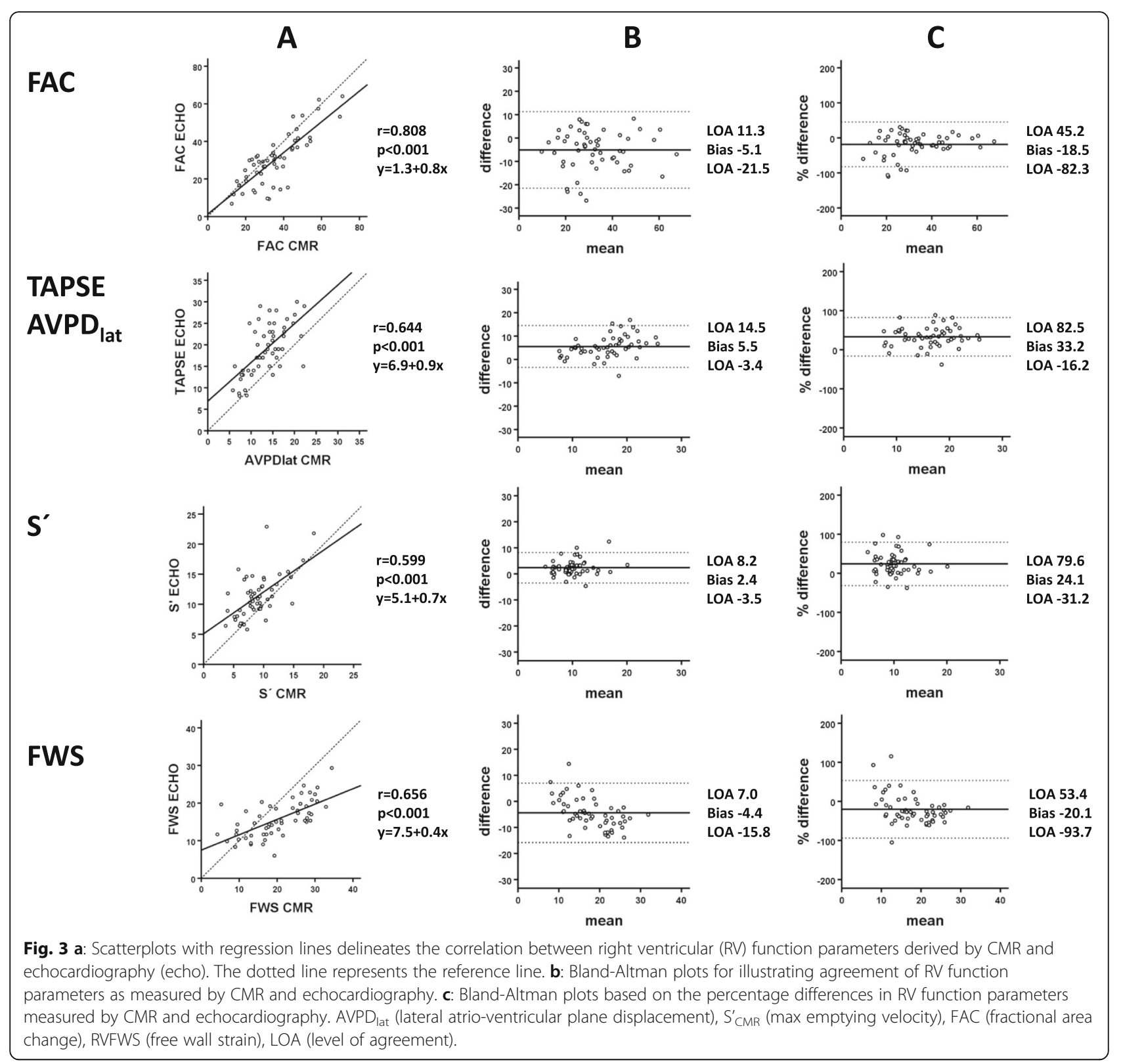

hypertension even when other RV parameters were impaired $[10,11]$. Methodologically, $S^{\prime}{ }_{C M R}$ is derived from the AVPD curve and is defined as the highest measured instantaneous velocity measured as the steepest systolic slope of the AVPD curve. The velocity at peak emptying $\left(S_{C M R}\right)$ could hence be considered as in parity to the peak systolic annular velocity from echocardiography $\mathrm{S}_{\text {echo }}$ [16]. $\mathrm{S}_{\mathrm{CMR}}{ }_{\mathrm{CM}}$ diminishes some of the limitations for $\mathrm{S}_{\text {echo }}$ such as angle-dependency and image quality. On the other hand, $\mathrm{S}_{\mathrm{CMR}}$ is acquired with a lower framerate than $S_{\text {echo }}^{\prime}$ and with a subsequent post processed smoothing of the curve. In comparison, $\mathrm{S}_{\text {echo }}$ is derived from pulsed-wave tissue-doppler imaging and with a high frame rate. The two methods cannot be considered methodologically fully interchangeable. In our study, S' showed the best agreement with narrow limits in absolute values between the methods. However, as with the other methods there was a systematic substantial relative bias and broad limits of agreement.

The strongest correlation between the modalities were shown by FAC and to our knowledge this is the first study to compare the two modalities. $\mathrm{FAC}_{\text {echo }}$ reflects both radial and longitudinal contribution to the overall RV function [3] and predicts both morbidity and mortality [30] in patients with pulmonary hypertension. Compared to echocardiographic assessment, delineation of the heavily trabeculated compact endocardial border is less challenging by CMR. One could argue that even if 


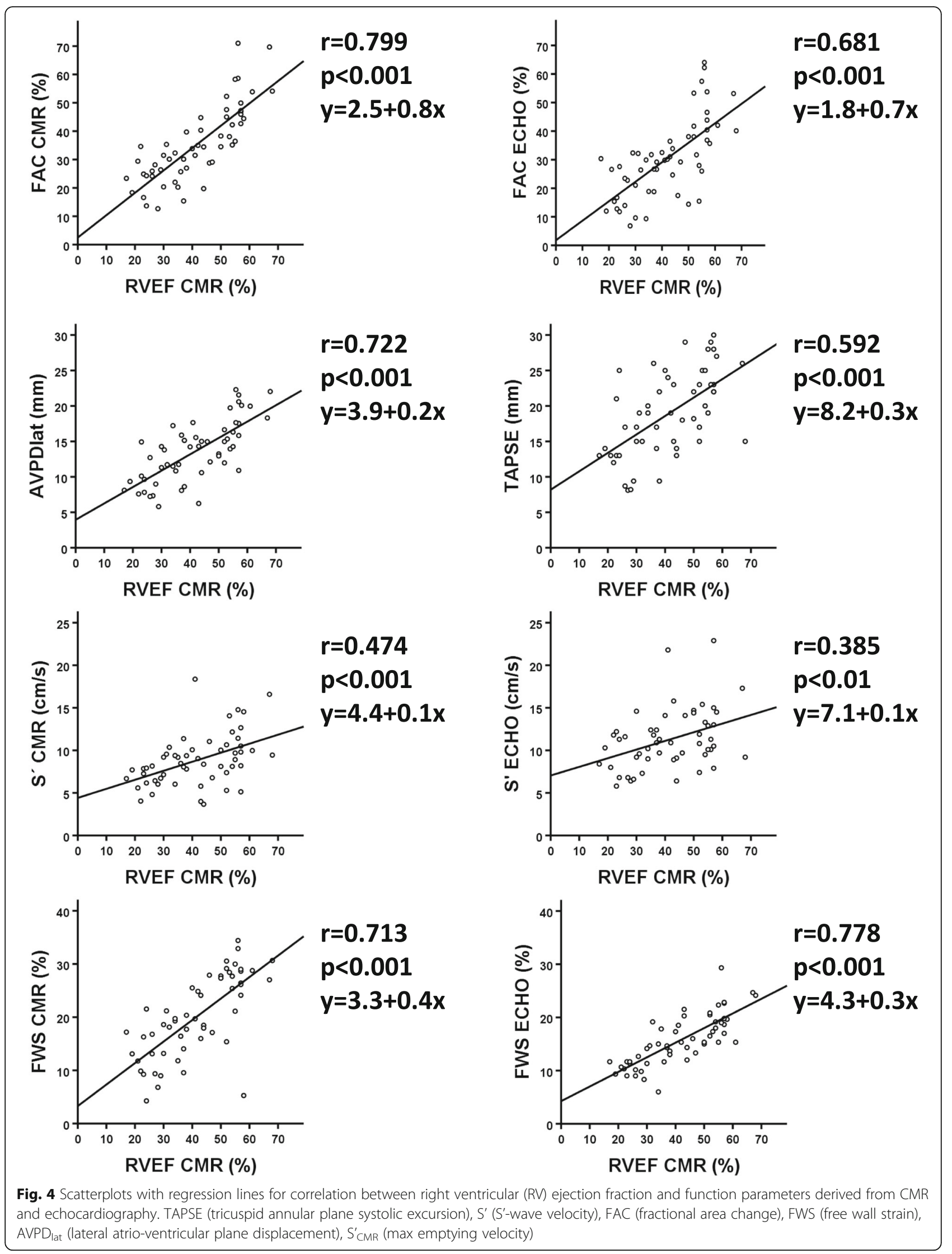


FAC is a surrogate for RVEF and there seems to be little point in measuring FAC by CMR. However, if RVEF is not applicable from CMR images owing to substantial artefacts or missing slices, FAC appears to be a good alternative to RV functional assessment.

In this study, FWS showed a moderate correlation between modalities. Prior studies have shown conflicting evidence as some are in concordance with ours [31], while others have found a stronger correlation [32, 33]. Strain values were on average $20 \%$ higher when measured by CMR with a greater spread of observed values (Fig. 3). The bias (absolute and relative) seems to be more pronounced in patients with lower strain values. There are several methodological reasons for strain values to differ between the modalities [34]. Theoretically, CMR strain assessment is advantageous to echocardiography as it is not vulnerable to poor acoustic windows [14]. However, this explanation for the bias in our study is unlikely since patients with echocardiographic poor acoustic window were excluded. One other reason could be that the software's are using different kinds of strain, i.e. CMR measures endocardial strain and the echocardiographic software uses mid-myocardial strain. The results in our study implies that echocardiographic and CMR evaluation of RV strain cannot be regarded as interchangeable.

\section{Comparison with $\operatorname{RVEF}_{\mathrm{CMR}}$}

While RVEF is invaluable in assessment of pulmonary hypertension, it is not a direct measure of RV contractility, RVEF requires augmentation with other global and regional parameters to assess the function on a myocardial level $[35,36]$. This forms a rationale for investigating the correlation between $\operatorname{RVEF}_{C M R}$ and other measurements parameters.

Our results are in concordance with previous studies on $\mathrm{FWS}_{\text {echo }}$ and $\mathrm{FAC}_{\text {echo/CMR }}[11,17]$ presenting a strong correlation with $\mathrm{RVEF}_{\mathrm{CMR}}$ with a modest correlation for TAPSE/AVPD lat and a weak correlation for $S^{\prime}$ echo compared to $\operatorname{RVEF}_{C M R}[11,17]$. As expected, the parameters measuring of area and volume change are closely related. In alignment with our study others have demonstrated a moderate correlation of $\mathrm{RVEF}_{\mathrm{CMR}}$ to $\mathrm{AVPD}_{\text {lat }}[17]$ and $\mathrm{FWS}_{\mathrm{CMR}}[31,37]$. The poor correlation between longitudinal measurements of RV function and $\mathrm{RVEF}_{\mathrm{CMR}}$ could be explained that RVEF is more related to fractional transverse movements than to longitudinal movements in patients with pulmonary hypertension [38]. This could also explain the strong correlation demonstrated between FAC and $\mathrm{RVEF}_{\mathrm{CMR}}$.

To our knowledge, this is the first study to evaluate the poor relationship of $\mathrm{RVEF}_{\mathrm{CMR}}$ to $\mathrm{S}_{\mathrm{CMR}}$, and to explore a comprehensive paired comparison of equivalent parameters of echocardiography and CMR.

\section{Clinical implications}

RV function is an important determinant of outcome in patients with pulmonary hypertension [1, 2] and $\mathrm{RVEF}_{\mathrm{CMR}}$ is a robust and precise method for risk assessment and clinical follow up. However, $\mathrm{RVEF}_{\mathrm{CMR}}$ is an incomplete method of assessing myocardial contraction as it only evaluates relative volume changes. Several studies have shown regional functional assessment of the RV has incremental value beyond $\operatorname{EF}[11,15,19]$. Longitudinal function has been proven of relevance for outcome irrespectively and independently of EF concerning the left ventricle $[35,39,40]$. Regarding RV, limited prognostic data is available at present. At present in clinical practice $\mathrm{FAC}_{\text {echo, }}$ TAPSE, $\mathrm{S}_{\text {echo }}$ and $\mathrm{FWS}_{\text {echo }}$ [3], and to some extent $A V P D_{\text {lat }}$ are used for assessment of systolic function although their prognostic values are not fully explored. FAC $C_{C M R}$, FWS $\mathrm{FMR}_{\mathrm{CMR}}$ and $\mathrm{S}_{\mathrm{CMR}}$ are new measures that are not yet implemented in clinical practice. To some extent the echocardiographic parameters have been showed to be associated to clinical outcome in pulmonary hypertension [3, 41], while the CMR equivalents are yet to be assessed, although data is accumulating [35, 36].

According to clinical practice in our center, the majority of patients evaluated for pulmonary hypertension are investigated within CMR of two main reasons: to exclude presence of congenital heart disease (including intracardial shunts) and also to have accurate measurements for RVEF and RV size since CMR is considered as gold standard for this purpose and these measures carry prognostic information [42, 43]. CMR are included in the current guidelines [20] when assessing the RV and our center is following the guidelines in that context. Our data implies that the utilization of both imaging modalities of regional measures can helpfully augment global assessment of RV function by $\mathrm{RVEF}_{\mathrm{CMR}}$, but the equivalent measures are not interchangeable at least in pulmonary hypertension. Clinical outcome data was not within the scope of this study. However, investigating which of the different RV functional markers in the present study is most predictive of outcome is of interest for future studies.

\section{Limitations}

There are some limitations in our study. This is a rather small study of 55 selected pulmonary hypertension patients since 35 were excluded due to atrial fibrillation $(n=15)$ and poor acoustic windows $(n=20)$. However, strain analysis on atrial fibrillation patients are at present not recommended and RV assessment by echocardiography is highly dependent on image quality. Therefore, one could debate which imaging modality is preferred for assessing RV function in this highly selected patient population. Echocardiography and CMR were performed 
contemporaneously, but not immediately so. Since RV function parameters are load-dependent, small changes in treatment (e.g. diuretic) may affect RV function parameters. However, median time was only 1 day with no cardiac events, medical changes, or clinical deterioration between examinations. $\mathrm{FWS}_{\text {echo }}$ was measured using an algorithm developed for the left ventricle. However, this method is standard procedure and has been propagated into guidelines $[3,44]$. On the other hand, $\mathrm{FWS}_{\mathrm{CMR}}$ was assessed in RV dedicated algorithm. Further standardization between different vendors for both CMR and echocardiography are required [34] as well as further studies before their utilization in routine clinical practice.

\section{Conclusion}

This study has demonstrated a moderate to strong correlation of regional CMR measurements to corresponding echocardiographic measures. However, biases and to some extent wide limits of agreement, exist between the modalities. Consequently, the equivalent measures are not interchangeable at least in patients with pulmonary hypertension. The echocardiographic parameter that showed best correlation with $\mathrm{RVEF}_{\mathrm{CMR}}$ was $\mathrm{FWS}_{\text {echo }}$. At present, $\mathrm{FAC}_{\text {echo }}$ and $\mathrm{FWS}_{\text {echo }}$ as well as $\mathrm{EF}_{\mathrm{CMR}}$ are the preferred methods to assess and follow up RV function in patients with pulmonary hypertension. Future investigations of the CMR right ventricular measures, beyond RVEF, are warranted.

\section{Supplementary information}

Supplementary information accompanies this paper at https://doi.org/10. 1186/s12872-020-01548-4.

Additional file 1: Table S1. Differences in characteristics and ventricular function parameters between gender, comorbidities and aetiology of pulmonary hypertension.

\section{Abbreviations \\ CMR: Cardiac magnetic resonance; Echo: Echocardiography; EF: Ejection fraction; RV: Right ventricle; FAC: Fractional area change; FWS: Free wall

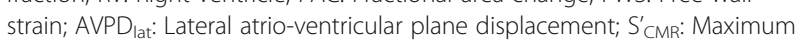 emptying velocity; $S_{\text {echo: }}^{\prime}$ '-wave velocity; TAPSE: Tricuspid annular plane systolic excursion}

\section{Acknowledgements}

We wish to acknowledge our appreciation of the support from the staff at the Echocardiographic Laboratory, The section for Heart Failure and Valvular Disease, VO Heart and Lung medicine, Skåne University Hospital and the staff at Lund University, Departments of Clinical Sciences Lund, Cardiology and Clinical Physiology, Lund, Sweden.

\section{Authors' contributions}

All authors (AWE, AL, RJ, Al, GJS, JW, GR, AR, CM and EO) contributed to the study conception and design of the work. Acquisition, analysis, interpretation of data and revision has been performed by AWE, Al, GJS, CM, AL and EO. The first draft of the manuscript was written by AWE. All authors (AWE, AL, RJ, Al, GJS, JW, GR, AR, CM and EO) have approved the submitted version and the modified version of the manuscript. All authors (AWE, AL, RJ, Al, GJS,
JW, GR, AR, CM and EO) have agreed that the work is appropriately investigated, resolved and resolution documented in the literature.

\section{Funding}

Open access funding provided by Lund University.

\section{Availability of data and materials}

The datasets generated and/or analysed during this study are not available for publications due to research subject confidentiality. They are available in a unidentified form from the corresponding author on reasonable request.

\section{Ethics approval and consent to participate}

The study complies with the Declaration of Helsinki and was approved by the regional department of the Swedish Ethical Review Authority (Dnr 2010/ 114, Dnr 2010/248 Dnr 2010/442). Written informed consent was given by the patients allowing analysis of all their clinical data including imaging, as granted in the ethical approval.

\section{Consent for publication}

Not applicable.

\section{Competing interests}

No conflicts of interest.

\section{Author details}

${ }^{1}$ Lund University, Department of Clinical Sciences Lund, Cardiology, Section for Heart Failure and Valvular Disease, Skane University Hospital, Lund, Sweden. ${ }^{2}$ Lund University, Department of Clinical Sciences Lund, Clinical Physiology, Skane University Hospital, Lund, Sweden. ${ }^{3}$ Liverpool Heart and Chest Hospital, Liverpool, UK.

Received: 6 March 2020 Accepted: 24 May 2020

Published online: 01 June 2020

\section{References}

1. Fine NM, Chen L, Bastiansen PM, Frantz RP, Pellikka PA, Oh JK, Kane GC. Outcome prediction by quantitative right ventricular function assessment in 575 subjects evaluated for pulmonary hypertension. Circ Cardiovasc Imaging. 2013;6(5):711-21. https://doi.org/10.1161/CIRCIMAGING.113.000640.

2. Simonneau G, Gatzoulis MA, Adatia I, Celermajer D, Denton C, Ghofrani A, Gomez Sanchez MA, Krishna Kumar R, Landzberg M, Machado RF, Olschewski H, Robbins IM, Souza R. Updated clinical classification of pulmonary hypertension. J Am Coll Cardiol. 2013;62(25 Suppl):D34-41. https://doi.org/10.1016/j.jacc.2013.10.029.

3. Lang RM, Badano LP, Mor-Avi V, Afilalo J, Armstrong A, Ernande L, Flachskampf FA, Foster E, Goldstein SA, Kuznetsova T, Lancellotti P, Muraru D, Picard MH, Rietzschel ER, Rudski L, Spencer KT, Tsang W, Voigt JU. Recommendations for cardiac chamber quantification by echocardiography in adults: an update from the American Society of Echocardiography and the European Association of Cardiovascular Imaging. J Am Soc Echocardiogr. 2015;28(1):1-39 e14. https://doi.org/10. 1016/j.echo.2014.10.003

4. Carlsson M, Ugander M, Heiberg $\mathrm{E}$, Arheden $\mathrm{H}$. The quantitative relationship between longitudinal and radial function in left, right, and total heart pumping in humans. Am J Phys Heart Circ Phys. 2007;293(1):H636-44. https://doi.org/10.1152/ajpheart.01376.2006.

5. Haddad F, Hunt SA, Rosenthal DN, Murphy DJ. Right ventricular function in cardiovascular disease, part I: anatomy, physiology, aging, and functional assessment of the right ventricle. Circulation. 2008;117(11):1436-48. https:// doi.org/10.1161/CIRCULATIONAHA.107.653576.

6. Ostenfeld E, Flachskampf FA. Assessment of right ventricular volumes and ejection fraction by echocardiography: from geometric approximations to realistic shapes. Echo Res Pract. 2015;2(1):R1-R11. https://doi.org/10.1530/ ERP-14-0077.

7. Hashimoto I, Watanabe K. Geometry-related right ventricular systolic function assessed by longitudinal and radial right ventricular contractions. Echocardiography (Mount Kisco, NY). 2016;33(2):299-306. https://doi.org/10. 1111/echo.13039.

8. Motoji Y, Tanaka H, Fukuda Y, Ryo K, Emoto N, Kawai H, Hirata K. Efficacy of right ventricular free-wall longitudinal speckle-tracking strain for predicting 
long-term outcome in patients with pulmonary hypertension. Circ J. 2013; 77(3):756-63. https://doi.org/10.1253/circj.cj-12-1083.

9. Lindqvist $\mathrm{P}$, Calcutteea $\mathrm{A}$, Henein M. Echocardiography in the assessment of right heart function. Eur J Echocardiogr. 2008;9(2):225-34. https://doi.org/10. 1016/j.euje.2007.04.002.

10. Werther Evaldsson A, Ingvarsson A, Waktare J, Smith GJ, Thilen U, Stagmo M, Roijer A, Radegran G, Meurling C. Right ventricular speckle tracking assessment for differentiation of pressure- versus volume-overloaded right ventricle. Clin Physiol Funct Imaging. 2018;38(5):763-71. https://doi.org/10. 1111/cpf.12477.

11. Werther Evaldsson A, Ingvarsson A, Smith JG, Radegran G, Roijer A, Waktare J, Ostenfeld E, Meurling C. Echocardiographic right ventricular strain from multiple apical views is superior for assessment of right ventricular systolic function. Clin Physiol Funct Imaging. 2019;39(2):168-76. https://doi.org/10. 1111/cpf.12552.

12. Katz J, Whang J, Boxt LM, Barst RJ. Estimation of right ventricular mass in normal subjects and in patients with primary pulmonary hypertension by nuclear magnetic resonance imaging. J Am Coll Cardiol. 1993;21(6):1475-81. https://doi.org/10.1016/0735-1097(93)90327-w.

13. Stephensen SS, Ostenfeld E, Steding-Ehrenborg K, Thilen U, Heiberg E, Arheden $\mathrm{H}$, Carlsson M. Alterations in ventricular pumping in patients with atrial septal defect at rest, during dobutamine stress and after defect closure. Clin Physiol Funct Imaging. 2018;38(5):830-9. https://doi.org/10. 1111/cpf.12491.

14. Schuster A, Hor KN, Kowallick JT, Beerbaum P, Kutty S. Cardiovascular magnetic resonance myocardial feature tracking: concepts and clinical applications. Circ Cardiovasc Imaging. 2016;9(4):e004077. https://doi.org/10 1161/CIRCIMAGING.115.004077.

15. Ostenfeld E, Stephensen SS, Steding-Ehrenborg K, Heiberg E, Arheden H, Radegran G, Holm J, Carlsson M. Regional contribution to ventricular stroke volume is affected on the left side, but not on the right in patients with pulmonary hypertension. Int J Cardiovasc Imaging. 2016;32(8):1243-53. https://doi.org/10.1007/s10554-016-0898-9.

16. Seemann F, Pahlm U, Steding-Ehrenborg K, Ostenfeld E, Erlinge D, DuboisRande JL, Jensen SE, Atar D, Arheden H, Carlsson M, Heiberg E. Timeresolved tracking of the atrioventricular plane displacement in cardiovascular magnetic resonance (CMR) images. BMC Med Imaging. 2017; 17(1):19. https://doi.org/10.1186/s12880-017-0189-5.

17. Hoette S, Creuze N, Gunther S, Montani D, Savale L, Jais X, Parent F, Sitbon O, Rochitte CE, Simonneau G, Humbert M, Souza R, Chemla D. RV fractional area change and TAPSE as predictors of severe right ventricular dysfunction in pulmonary hypertension: a CMR study. Lung. 2018;196(2):157-64. https:// doi.org/10.1007/s00408-018-0089-7.

18. de Siqueira ME, Pozo E, Fernandes VR, Sengupta PP, Modesto K, Gupta SS, Barbeito-Caamano C, Narula J, Fuster V, Caixeta A, Sanz J. Characterization and clinical significance of right ventricular mechanics in pulmonary hypertension evaluated with cardiovascular magnetic resonance feature tracking. J Cardiovasc Magn Reson. 2016;18(1):39. https://doi.org/10.1186/ s12968-016-0258-x.

19. Lindholm A, Hesselstrand R, Radegran G, Arheden H, Ostenfeld E. Decreased biventricular longitudinal strain in patients with systemic sclerosis is mainly caused by pulmonary hypertension and not by systemic sclerosis per se. Clin Physiol Funct Imaging. 2019;39(3):215-25. https://doi.org/10.1111/cpf.12561.

20. Galie N, Humbert M, Vachiery JL, Gibbs S, Lang I, Torbicki A, Simonneau G, Peacock A, Vonk Noordegraaf A, Beghetti M, Ghofrani A, Gomez Sanchez MA, Hansmann G, Klepetko W, Lancellotti P, Matucci M, McDonagh T, Pierard LA, Trindade PT, Zompatori M, Hoeper M, Group ESCSD. 2015 ESC/ ERS guidelines for the diagnosis and treatment of pulmonary hypertension: the joint task force for the diagnosis and treatment of pulmonary hypertension of the European Society of Cardiology (ESC) and the European Respiratory Society (ERS): endorsed by: Association for European Paediatric and Congenital Cardiology (AEPC), International Society for Heart and Lung Transplantation (ISHLT). Eur Heart J. 2016;37(1):67-119. https://doi.org/10. 1093/eurhearti/ehv317.

21. Heiberg E, Sjogren J, Ugander M, Carlsson M, Engblom H, Arheden H. Design and validation of segment--freely available software for cardiovascular image analysis. BMC Med Imaging. 2010;10:1. https://doi.org/ 10.1186/1471-2342-10-1.

22. Schulz-Menger J, Bluemke DA, Bremerich J, Flamm SD, Fogel MA, Friedrich MG, Kim RJ, von Knobelsdorff-Brenkenhoff F, Kramer CM, Pennell DJ, Plein S,
Nagel E. Standardized image interpretation and post processing in cardiovascular magnetic resonance: Society for Cardiovascular Magnetic Resonance (SCMR) board of trustees task force on standardized post processing. J Cardiovasc Magn Reson. 2013;15:35. https://doi.org/10.1186/ 1532-429X-15-35.

23. Seemann F, Baldassarre LA, Llanos-Chea F, Gonzales RA, Grunseich K, Hu C, Sugeng L, Meadows J, Heiberg E, Peters DC. Assessment of diastolic function and atrial remodeling by MRI - validation and correlation with echocardiography and filling pressure. Physiol Rep. 2018;6(17):e13828. https://doi.org/10.14814/phy2.13828.

24. Mukaka MM. Statistics corner: a guide to appropriate use of correlation coefficient in medical research. Malawi Med J. 2012;24(3):69-71.

25. Bland JM, Altman DG. Statistical methods for assessing agreement between two methods of clinical measurement. Lancet (London, England). 1986; 1(8476):307-10.

26. Petersen SE, Aung N, Sanghvi MM, Zemrak F, Fung K, Paiva JM, Francis JM, Khanji MY, Lukaschuk E, Lee AM, Carapella V, Kim YJ, Leeson P, Piechnik SK, Neubauer $S$. Reference ranges for cardiac structure and function using cardiovascular magnetic resonance (CMR) in Caucasians from the UK biobank population cohort. J Cardiovasc Magn Reson. 2017;19(1):18. https:// doi.org/10.1186/s12968-017-0327-9.

27. Kawel-Boehm N, Maceira A, Valsangiacomo-Buechel ER, Vogel-Claussen J, Turkbey EB, Williams R, Plein S, Tee M, Eng J, Bluemke DA. Normal values for cardiovascular magnetic resonance in adults and children. J Cardiovasc Magn Reson. 2015;17:29. https://doi.org/10.1186/s12968-015-0111-7.

28. Galie N, Hoeper MM, Humbert M, Torbicki A, Vachiery JL, Barbera JA, Beghetti M, Corris P, Gaine S, Gibbs JS, Gomez-Sanchez MA, Jondeau G, Klepetko W, Opitz C, Peacock A, Rubin L, Zellweger M, Simonneau G, Guidelines ESCCFP. Guidelines for the diagnosis and treatment of pulmonary hypertension: the task force for the diagnosis and treatment of pulmonary hypertension of the European Society of Cardiology (ESC) and the European Respiratory Society (ERS), endorsed by the International Society of Heart and Lung Transplantation (ISHLT). Eur Heart J. 2009;30(20):2493-537. https:// doi.org/10.1093/eurheartj/ehp297.

29. van Kessel M, Seaton D, Chan J, Yamada A, Kermeen F, Hamilton-Craig C, Butler T, Sabapathy S, Morris N. Prognostic value of right ventricular free wall strain in pulmonary hypertension patients with pseudo-normalized tricuspid annular plane systolic excursion values. Int J Cardiovasc Imaging. 2016;32(6):905-12. https://doi.org/10.1007/s10554-016-0862-8.

30. Ghio S, Klersy C, Magrini G, D'Armini AM, Scelsi L, Raineri C, Pasotti M, Serio A, Campana C, Vigano M. Prognostic relevance of the echocardiographic assessment of right ventricular function in patients with idiopathic pulmonary arterial hypertension. Int J Cardiol. 2010;140(3):272-8. https://doi. org/10.1016/j.jijcard.2008.11.051.

31. Freed BH, Tsang W, Bhave NM, Patel AR, Weinert L, Yamat M, Vicedo BM, Dill K, Mor-Avi V, Gomberg-Maitland M, Lang RM. Right ventricular strain in pulmonary arterial hypertension: a 2D echocardiography and cardiac magnetic resonance study. Echocardiography (Mount Kisco, NY). 2015;32(2): 257-63. https://doi.org/10.1111/echo.12662.

32. Onishi T, Saha SK, Delgado-Montero A, Ludwig DR, Onishi T, Schelbert EB, Schwartzman D, Gorcsan J 3rd. Global longitudinal strain and global circumferential strain by speckle-tracking echocardiography and featuretracking cardiac magnetic resonance imaging: comparison with left ventricular ejection fraction. J Am Soc Echocardiogr. 2015;28(5):587-96. https://doi.org/10.1016/j.echo.2014.11.018.

33. Riffel JH, Keller MG, Aurich M, Sander Y, Andre F, Giusca S, Aus dem Siepen F, Seitz S, Galuschky C, Korosoglou G, Mereles D, Katus HA, Buss SJ. Assessment of global longitudinal strain using standardized myocardial deformation imaging: a modality independent software approach. Clin Res Cardiol. 2015;104(7):591-602. https://doi.org/10.1007/s00392-015-0822-7.

34. Amzulescu MS, De Craene M, Langet H, Pasquet A, Vancraeynest D, Pouleur AC, Vanoverschelde JL, Gerber BL. Myocardial strain imaging: review of general principles, validation, and sources of discrepancies. Eur Heart J Cardiovasc Imaging. 2019;20(6):605-19. https://doi.org/10.1093/ehjci/jez041.

35. Gjesdal O, Yoneyama K, Mewton N, Wu C, Gomes AS, Hundley G, Prince M, Shea S, Liu K, Bluemke DA, Lima JA. Reduced long axis strain is associated with heart failure and cardiovascular events in the multi-ethnic study of atherosclerosis. J Magn Reson Imaging. 2016;44(1):178-85. https://doi.org/10.1002/jmri.25135.

36. Chitiboi T, Axel L. Magnetic resonance imaging of myocardial strain: a review of current approaches. J Magn Reson Imaging. 2017;46(5):1263-80. https://doi.org/10.1002/jmri.25718. 
37. Oyama-Manabe N, Sato T, Tsujino I, Kudo K, Manabe O, Kato F, Osman NF Terae $\mathrm{S}$. The strain-encoded (SENC) MR imaging for detection of global right ventricular dysfunction in pulmonary hypertension. Int J Cardiovasc Imaging. 2013;29(2):371-8. https://doi.org/10.1007/s10554-012-0105-6.

38. Kind T, Mauritz GJ, Marcus JT, van de Veerdonk M, Westerhof N, VonkNoordegraaf A. Right ventricular ejection fraction is better reflected by transverse rather than longitudinal wall motion in pulmonary hypertension. J Cardiovasc Magn Reson. 2010;12:35. https://doi.org/10.1186/1532-429X-12-35.

39. Rangarajan V, Chacko SJ, Romano S, Jue J, Jariwala N, Chung J, Farzaneh-Far A. Left ventricular long axis function assessed during cine-cardiovascular magnetic resonance is an independent predictor of adverse cardiac events. J Cardiovasc Magn Reson. 2016;18(1):35. https:/doi.org/10.1186/s12968-016-0257-y.

40. Romano S, Judd RM, Kim RJ, Kim HW, Klem I, Heitner JF, Shah DJ, Jue J, Farzaneh-Far A. Left ventricular long-Axis function assessed with cardiac cine MR imaging is an independent predictor of all-cause mortality in patients with reduced ejection fraction: a multicenter study. Radiology. 2018;286(2):452-60. https://doi.org/10.1148/radiol.2017170529.

41. Lu KJ, Chen JX, Profitis K, Kearney LG, DeSilva D, Smith G, Ord M, Harberts S, Calafiore P, Jones E, Srivastava PM. Right ventricular global longitudinal strain is an independent predictor of right ventricular function: a multimodality study of cardiac magnetic resonance imaging, real time three-dimensional echocardiography and speckle tracking echocardiography. Echocardiography (Mount Kisco, NY). 2015;32(6):966-74. https://doi.org/10.1111/echo.12783

42. van de Veerdonk MC, Marcus JT, Westerhof N, de Man FS, Boonstra A, Heymans MW, Bogaard HJ, Vonk Noordegraaf A. Signs of right ventricular deterioration in clinically stable patients with pulmonary arterial hypertension. Chest. 2015;147(4):1063-71. https://doi.org/10.1378/ chest.14-0701

43. van Wolferen SA, Marcus JT, Boonstra A, Marques KM, Bronzwaer JG, Spreeuwenberg MD, Postmus PE, Vonk-Noordegraaf A. Prognostic value of right ventricular mass, volume, and function in idiopathic pulmonary arterial hypertension. Eur Heart J. 2007;28(10):1250-7. https://doi.org/10.1093/ eurhearti/eh/477.

44. Badano LP, Kolias TJ, Muraru D, Abraham TP, Aurigemma G, Edvardsen T, D'Hooge J, Donal E, Fraser AG, Marwick T, Mertens L, Popescu BA, Sengupta PP, Lancellotti P, Thomas JD, Voigt JU, Industry r, Reviewers: This document was reviewed by members of the ESDC. Standardization of left atrial, right ventricular, and right atrial deformation imaging using two-dimensional speckle tracking echocardiography: a consensus document of the EACVI/ASE/industry task force to standardize deformation imaging. Eur Heart J Cardiovasc Imaging. 2018;19(6):591600. https://doi.org/10.1093/ehjci/jey042.

\section{Publisher's Note}

Springer Nature remains neutral with regard to jurisdictional claims in published maps and institutional affiliations.

\section{Ready to submit your research? Choose BMC and benefit from:}

- fast, convenient online submission

- thorough peer review by experienced researchers in your field

- rapid publication on acceptance

- support for research data, including large and complex data types

- gold Open Access which fosters wider collaboration and increased citations

- maximum visibility for your research: over $100 \mathrm{M}$ website views per year

At BMC, research is always in progress.

Learn more biomedcentral.com/submissions 